\title{
TOPOLOGY ANALYSIS OF BICYCLE RIM BRAKE PAD TO IMPROVE BRAKING PERFORMANCE
}

\author{
Le-Onn Keong ${ }^{1}$ and Choe-Yung Teoh ${ }^{1^{*}}$ \\ ${ }^{1}$ Faculty of Engineering, \\ Tunku Abdul Rahman University College. \\ Email: teohcy@tarc.edu.my \\ Phone: +60341450123; Fax: +60341423166
}

\begin{abstract}
Various parameters of rubber brake pad tribology will affect the braking performance of a rim brake system of a bicycle. Out of those, three main parameters are contact length of brake pad, surface topology of friction surface, and the thickness of rim brake pad. The goals of this study are to improve the braking performance of rim brakes to have better friction performance while retaining its simplicity of manufacturing and to investigate the effect on friction performance through the modifications of external dimensions and surface topology of rim brakes. Moreover, through this study, it can reveal which topology modifications of the rubber brake pad will have the most significance effect towards friction performance. Experimental measurement is used to obtain the friction properties and then parametric study was carried out numerically to obtain the braking performance of the rubber brake pad. The parametric study was simulated in ANSYS Transient Structural analysis. Taguchi design method was used for quantitatively identifying the right inputs and parameter levels. The results showed that smaller groove and smaller width contribute to higher friction performance. Stress concentration occurs at the edge of groove; hence, by reducing number of groove, it allows higher braking force to be generated. Location of groove concentration appears to have insignificance effect to the friction performance. Through the topology modifications, it improves the braking performance by 3\%. As for external dimension, thick rubber brake pad will not demonstrate any improvement and longer contact length will demonstrate higher friction force. However, it has to be bounded by the practicality of the dimension. Upon modifications at the external dimension, it has an improvement of $64 \%$ in braking performance.
\end{abstract}

Keywords: Rubber brake pad, friction force, coefficient of friction, surface topology, tribology, groove pattern

\section{INTRODUCTION}

Braking performance of a bicycle is important as it is a crucial mechanism to stop the bicycle in an emergency event. In order to obtain a higher performance brake pad, it requires brake pad materials that are made from various combinations of highend braking material and it will increase the price of the brake pad. Hence, most users will prefer not to purchase high performance brake pad due to the cost. Braking performance of a conventional rim brakes (rubber brake pads) is not as efficient as a standard disc brake system. Commonly available rubber brake pad (RBP) in the market has low friction and low braking performance. The poor performance leads to lack of power in braking and as a results, slippage and sliding may occur during braking. 
The main objectives of this research are to improve the performance of rim brakes to have higher friction performance through parametric study, to investigate the effect on friction performance through the modifications of external dimension of rim brakes, and to analyse the effect of different extent of tribology features of rim brake pad acted on the rim. The contribution of the research is to improve the braking performance and friction performance of a rim brakes in to improve the safety of braking system without the necessary to increase additional cost by putting the interest of the study on the tribology properties and dimension alteration. The study is going to carry out fully on rim brakes or rubber brake pads, whereas many previous studies are completed only to further improve disc brake.

\section{METHODOLOGY}

\section{Experimental Test Bench Setup}

In order to obtain the coefficient of friction between the rubber brake pad and aluminium rim, a test bench is constructed (Figure 1). The load cell used is an S-type structure (DYLY-103) that is suitable for tension and compression. It has the sensitivity of $2.0 \pm 0.005 \mathrm{mV} / \mathrm{V}$. The load cell is connected to a digital reader.

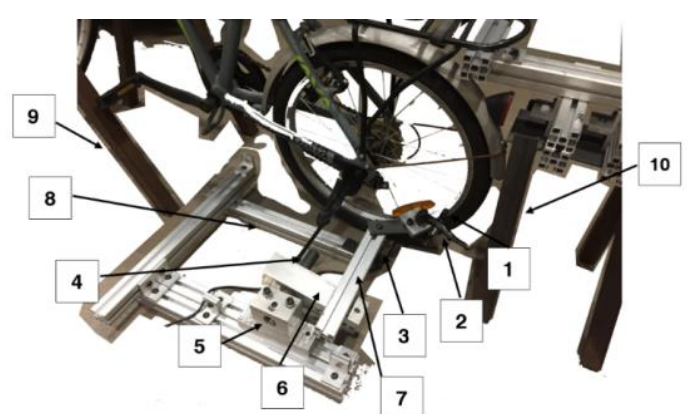

Figure 1. 1.Rubber brake pad, 2.Brake lever, 3.Load cell setup, 4.Shaft, 5.Bearing housing with bearing, 6.Aluminium profile, 7.Longitudinal aluminium profile, 8.Support aluminium profile,

9.Front stand, 10.Back stand

\section{Numerical Simulation Setup}

Reaction forces on the surface of contact, deformation at groove edge, and shear stress generated at the surface of contact are captured and recorded from the ANSYS simulation results. Figure 2 shows the 3D model used in the study.

\section{Parametric Study of Rubber Brake Pad Model}

Rubber brake pad will undergo parameters change to further improved braking performance by altering a few crucial parameters that could affect the braking efficiency of the rubber brake pad.

\section{Changes of Contact Length towards Friction Force Performance}

The length of the brake pad is varied and the effect on the braking performance respond to the length variation is studied. This research will analyse the suggested length of brake pad as stated in Table 1 . 


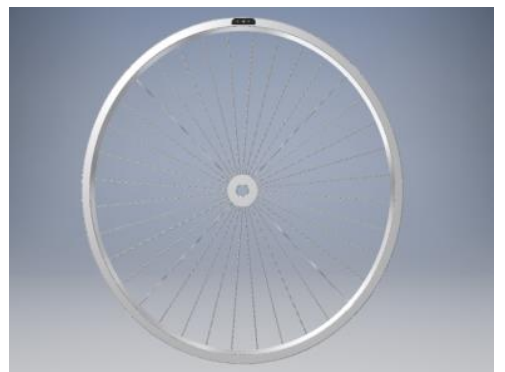

Figure 2. Front view of the model. Black represent rubber brake pad and aluminium represent rim.

Table 1. Contact lengths that will be used to determine the best contact length

\begin{tabular}{ll} 
Set & Length $(\mathrm{mm})$ \\
\hline 1 & 54 \\
2 & 57.4 \\
3 & 70 \\
\hline
\end{tabular}

Alteration of Groove Pattern Topology towards Friction Force Performance

A number of properties of groove pattern topology are modified in this study. Groove depths are varies between $3 \mathrm{~mm}$ to $9 \mathrm{~mm}$, number of straight grooves are varies between 3 to 6 , groove widths are varies between $3 \mathrm{~mm}$ to $7 \mathrm{~mm}$, and location of grooves are separated to symmetrical, leading edge, and trailing edge.

\section{Changes of Thickness of Brake Pad towards Friction Force Performance}

A thicker brake pad allows more wear and deeper groove tolerance since it has the allowable thickness to be machined but tends to cause more vibration to occur when load applied. Suggested thickness of brake pad are $14 \mathrm{~mm}, 20 \mathrm{~mm}$, and $25 \mathrm{~mm}$ for baseline, set 1 , and set 2 respectively.

\section{Materials Properties of Rubber Brake Pad and Aluminium Rim}

The material properties of the aluminium rim and rubber brake pad for both experimental measurement and numerical simulation (Table 2) has to be matched as close as possible to reduce inaccuracy in reading.

Table 2. Materials parameters used during the numerical analysis (Shackelford et al., 2016) (Ramezani et al., 2012)

\begin{tabular}{lll}
\hline & Aluminium Rim & Rubber Brake Pad \\
\hline Young Modulus $(\mathrm{GPa})$ & 70 & 0.015 \\
Poisson's Ratio & 0.33 & 0.499 \\
Density $\left(\mathrm{kg} / \mathrm{m}^{3}\right)$ & 2700 & 1500 \\
\hline
\end{tabular}

\section{RESULTS AND DISCUSSION}

The tribology properties between a rubber brake pad and an aluminium rim are represented by the coefficient of friction (COF). The COF is determined at the 
experimental stage where a custom bench is fabricated to harvest the applied normal force (Table 3) and resultant friction force during the braking event.

\section{Experimental Measurement of Normal Force and Friction Force}

The properties between both of the surfaces is well portrayed by the COF. Thus, the numerical simulation will then use the obtained COF (Table 4) during the setup in order to mimic the surface condition of the rubber brake pad and aluminium rim without necessary of detailed study on the surface.

Table 3. Applied force obtained during execution of braking process

\begin{tabular}{cc}
\hline Trial & Applied Normal Force $(\mathrm{N})$ \\
\hline 1 & 118 \\
2 & 106 \\
3 & 107 \\
4 & 109 \\
5 & 92 \\
\hline Average & 106.4 \\
\hline
\end{tabular}

\section{Numerical Analysis on the Friction Performance}

First set of simulation (Stage 1) results is prepared and run by varying four major topology parameters of a rubber brake pad using Taguchi's Method. Table 5 shows the friction force generated at the effective contact surface between the bicycle aluminium rim and the surface of the rubber brake pad. The deformation is labelled as "DEFORM" and its results are highly inaccurate. Rubber brake pad configuration of "333A" has the largest friction force among the configurations. It has groove depth of 3 $\mathrm{mm}, 3$ straight grooves, and $3 \mathrm{~mm}$ groove width. The ranking then followed by 533A and $333 \mathrm{C}$.

Table 4. Friction force obtained from the reading of the load cell

\begin{tabular}{ccc}
\hline Trial & Friction Force $(\mathrm{N})$ & Coefficient of Friction \\
\hline 1 & 39.0 & 0.3665 \\
2 & 44.0 & 0.4135 \\
3 & 42.0 & 0.3947 \\
4 & 42.0 & 0.3947 \\
5 & 46.0 & 0.4323 \\
\hline Average & 42.6 & 0.4004 \\
\hline
\end{tabular}

Table 5. Friction force obtained from numerical analysis during Stage 1

\begin{tabular}{|c|c|c|c|c|c|c|}
\hline \multirow{3}{*}{ Set } & \multirow{3}{*}{$\begin{array}{c}\text { Groove } \\
\text { Depth } \\
(\mathrm{mm})\end{array}$} & \multirow{3}{*}{$\begin{array}{c}\text { Number of } \\
\text { Straight } \\
\text { Grooves }\end{array}$} & \multirow{3}{*}{$\begin{array}{l}\text { Groove } \\
\text { Width } \\
(\mathrm{mm})\end{array}$} & \multicolumn{3}{|c|}{ Friction Force $(\mathrm{N})$} \\
\hline & & & & \multicolumn{3}{|c|}{ Location of Grooves Concentration } \\
\hline & & & & Symmetrical $(S)$ & Trailing Edge (A) & Leading Edge (C) \\
\hline 1 & 3 & 3 & 3 & 28.27 & 29.09 & 28.33 \\
\hline 2 & 5 & 3 & 3 & 26.75 & 28.37 & 28.12 \\
\hline 3 & 7 & 3 & 3 & 24.82 & DEFORM & DEFORM \\
\hline 4 & 9 & 3 & 3 & 23.26 & DEFORM & DEFORM \\
\hline 5 & 3 & 5 & 3 & 24.95 & 24.98 & 24.78 \\
\hline 6 & 5 & 5 & 3 & 24.94 & 23.19 & 24.25 \\
\hline 7 & 7 & 5 & 3 & DEFORM & DEFORM & DEFORM \\
\hline 8 & 9 & 5 & 3 & DEFORM & DEFORM & DEFORM \\
\hline
\end{tabular}




\begin{tabular}{ccccccc}
9 & 3 & 3 & 5 & DEFORM & 24.01 & 17.45 \\
10 & 5 & 3 & 5 & 21.96 & 23.96 & 24.72 \\
11 & 7 & 3 & 5 & 20.79 & 25.15 & DEFORM \\
12 & 9 & 3 & 5 & 19.92 & DEFORM & DEFORM \\
13 & 3 & 3 & 7 & 19.35 & 19.67 & 20.44 \\
14 & 5 & 3 & 7 & 17.98 & 20.64 & 20.24 \\
15 & 7 & 3 & 7 & 17.85 & DEFORM & DEFORM \\
16 & 9 & 3 & 7 & DEFORM & DEFORM & DEFORM \\
\hline
\end{tabular}

\section{Friction Performance Respond on Groove Width Variation}

Compared to a $5 \mathrm{~mm}$ groove width, the side walls of a $3 \mathrm{~mm}$ groove width are well supported and the fillet from the base of the groove act as a buttress for the side walls (Consolacion et al., 1995).

\section{Friction Performance Respond on Number of Straight Groove (Groove Density)}

Stress concentration exist when there is discontinuity in geometry. Higher number of grooves demonstrates a lower shear stress exist at the edge of each groove (contact point during deformation of groove) (Nakashima et al., 2009).

\section{Significance Location of Groove Concentration}

The results demonstrates the position where the concentration of grooves exist do not affect the results significantly. The variations between the different location for the same series are small ( $4 \%$ variation) and it is concluded that it is not the dominance feature in a rubber brake pad. One-way ANOVA test results also shows the feature do not give a significance score $(p<0.05)$ towards the friction performance of the rubber brake pad.

\section{Depth of Groove on Friction Performance}

From multiple results obtained, it is cleared that most groove depth that is more than $5 \mathrm{~mm}$ of depth will suffer deformation and failure upon loading by the surface friction. While for $3 \mathrm{~mm}$ and $5 \mathrm{~mm}$, groove depth of $5 \mathrm{~mm}$ tend to have slightly higher flex when it is loaded, as seen in Figure 3.
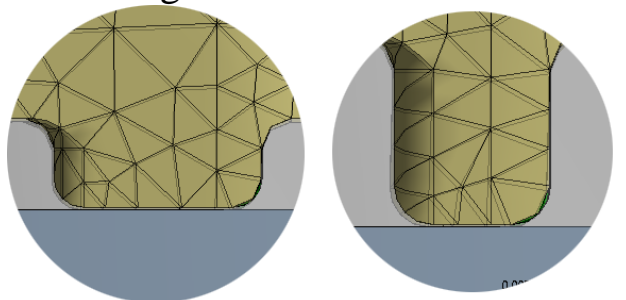

Figure 3. One of the contact point of "353A" (left, enlarged-view) and "553A" (right). The "553A" shows a higher flex to the left hence reducing the effective contact area on the right.

In second stage of numerical analysis, it shows larger contact length will contribute to higher friction force performance. This is largely due to larger area of surface rubbing on the surface of the rim. However, in practicality of manufacturing and usage, it is not advisable as it will always limits by the radius of the rim and the cost to manufacture as it requires more raw materials for a large rubber brake pad. Apart from that, thicker rubber brake pad will not contribute to any better friction force performance, even for the same contact length. The findings is in-line with what Smith 
(2011) and Sanches et al. (2017) demonstrates in their research where it shows no noticeable increment in friction force when thickness of rubber increases.

Hence, all in all, it reveals that longer contact length with the same thickness as baseline model or RBP: 333A-CA, demonstrates the highest friction force performance.

\section{CONCLUSION}

For a rubber brake pad topology features, not all features give a significance changes to the friction performance. Through the numerical analysis, it demonstrates different changes for different topology features;

a) Smaller groove depth will result in higher friction force due to lesser flex occurred at the groove edge; hence it will not reduce the contact area when it is subjected to loading.

b) Three number of grooves perform better than five number of grooves. This is due to stress concentration exist when there is groove due to geometric discontinuity.

c) Smaller groove width demonstrates higher friction force too due to the geometric support at the base of the groove.

d) Location of groove concentration does not give significance difference in the friction performance.

For dimensional changes, larger contact length will result in higher friction performance and thicker rubber brake pad will result in no negative friction performance. Comparing with the baseline model (333S), the modified version of rubber brake pad during Stage One improved by $3 \%$ (333A), and Stage Two modification improved significantly by $64 \%$ (333A-CA) in terms of friction force performance

\section{ACKNOWLEDGEMENTS}

I would like to thank Tunku Abdul Rahman University College (TARUC) for organising such hands-on oriented final year project. Besides that, I would love to say a million of thank you to my supervisor, Dr. Teoh Choe Yung, for his unconditional supports throughout this project. Lastly, I would like to express my fullest gratitude and appreciation to all of my family members, especially for my parents for their wholehearted supports and concerns.

\section{REFERENCES}

[1] Consolacion, R.E., Brayer, R.R. and Croyle, W.L., The Goodyear Tire \& Rubber Company, 1995. Tread for a tire. U.S. Patent 5,407,005.

[2] Nakashima, H., Takatsu, Y., Shinone, H., Matsukawa, H. and Kasetani, T., 2009. FE-DEM analysis of the effect of tread pattern on the tractive performance of tires operating on sand. Journal of Mechanical Systems for Transportation and Logistics, 2(1), pp.55-65.

[3] Ramezani, M. and Ripin, Z.M., 2012. Rubber-pad forming processes: Technology and applications. Elsevier.

[4] Sanches, A.O., Kanda, D.H.F., Malmonge, L.F., da Silva, M.J., Sakamoto, W.K. and Malmonge, J.A., 2017. Synergistic effects on polyurethane/lead zirconate titanate/carbon black three-phase composites. Polymer Testing, 60, pp.253-259.

[5] Smith, R.H., 2011. A Load-Independent, Adhesion-Related Rubber Friction Force?. The Journal of Adhesion, 87(11), pp.1112-1123. 